УДК 665.63; https://doi.org/10.37878/2708-0080/2020-5.031

\title{
ИССЛЕДОВАНИЕ ПРОЦЕССА ГИДРОДИНАМИЧЕСКОЙ АКТИВАЦИИ ТЯЖЕЛОГО НЕФТЯНОГО СЫРЬЯ
}

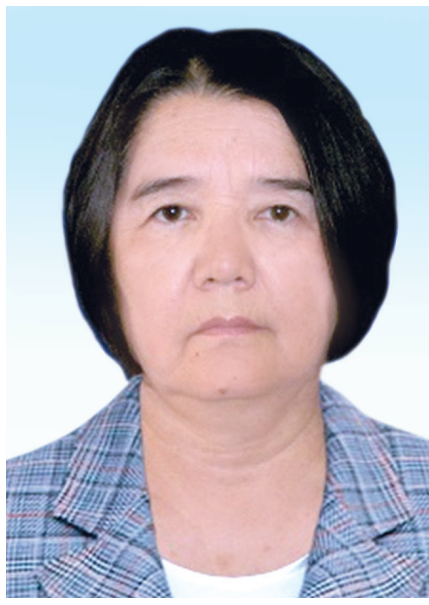

С.Б. НУРЖАНОВА ${ }^{1,2}$, кандидат химических наук, старший научный сотрудник

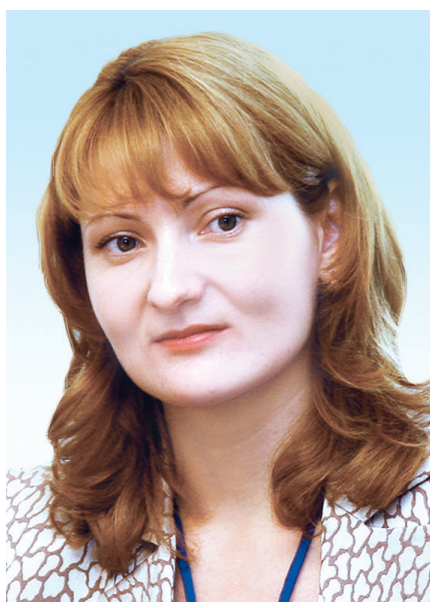

Е.в. СолодОВА ${ }^{1,2}$, кандидат биологических наук, ведущий научный сотрудник

A.В. ШИРИнСКИХ ${ }^{1 *}$, кандидат химических наук, ведущий научный сотрудник

А.3. АБИЛМАГЖАНОВ ${ }^{1}$, кандидат химических наук, первый заместитель генерального директора

'АО «ИНСТИТУТ ТОПЛИВА, КАТАЛИЗА И ЭЛЕКТРОХИМИИ ИМ. Д.В. СОКОЛЬСКОГО» Республика Казахстан, 050010, г. Алматы, ул. Д.А. Кунаева, 142

2КАЗАХСКИЙ НАЦИОНАЛЬНЫЙ УНИВЕРСИТЕТ ИМ. АЛЬ-ФАРАБИ

Республика Казахстан, 050040, г. Алматы, пр. аль-Фараби, 71

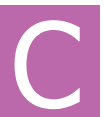

огласно мировым прогнозам, в связи с истощением запасов легких нефтей в недалекой перспективе возникнет проблема переработки исключительно тяжелого углеводородного сырья. Для решения этого вопроса необходимо совершенствовать или частично изменять существующие технологии нефтепереработки, например, путем интегрирования классических и нетрадиционных методов.

В случае использования механо-волнового воздействия на обрабатываемое нефтяное сырье, имеет место деструкция его молекулярных структур, протекание химических реакций, облегчающих процесс более глубокой переработки.

Целью статьи является исследование процессов превращений высокомолекулярных компонентов тяжелого нефтяного сырьяпри термомеханическом - гидродинамическом воздействии на него.

Проведена оценка возможности мягкого крекинга тяжелой нефти и ее смесей с нефтяными остатками (битум, мазут) при гидродинамической обработке в ротор- 
ном активаторе. В процессе гидродинамического воздействия на нефтяное сырье происходит разрыв длинноцепочных молекул углеводородных соединений, т. е. изменяется их исходный химический состав.

На основании исследования физико-химических свойств нефтяного сырья исходной тяжелой нефти и нефтяных остатков, характера их фракционного состава при атмосферной разгонке, предложен механо-волновой-гидродинамический метод переработки без использования реагентов и катализаторов.

Разрабатываемая технология может обеспечить эффективное решение задач по углублению переработки тяжелой нефти: увеличению выхода дистиллятов, снижение количества нефтяных кубовых остатков, при энергетически малозатратной и экологической безопасности технологии производства.

\section{АКТУАЛЬНОСТЬ.}

По современным оценкам, остаточные запасы легких нефтей будут исчерпаны в течение следующих 50 лет. Удобные для добычи и переработки, они достигли пика добычи, вступают в период спада, и лишь небольшое количество нефтяных бассейнов остается для перспективной разработки. Между тем в различных залежах по всему миру содержится значительное количество тяжелых и сверхтяжелых нефтей. природных битумов, асфальтитов и др., запасы которых составляют более 810 миллиардов тонн, что по объему сопоставимо, а, возможно, и превосходит традиционные запасы легких и средних нефтей.

Мировым лидером по запасам тяжелой нефти (ТН) является Канада, на втором месте - Венесуэла, на третьем - Россия, и именно эти страны одними из первых проявили интерес к переработке тяжелого нефтяного сырья [1-3].

На территории Казахстана также в большом количестве встречаются месторождения высоковязкой нефти и природных битумов (ВВН и ПБ),относящихся к категории трудноизвлекаемых. Наиболее крупными являются нефтегазовые месторождения Каражанбас, Северные Бозаши, Каламкас с общими остаточными извлекаемыми запасами порядка 160 млн т [4].

Возросший интерес к тяжелым нефтям, в частности их переработки, требует проведения различных исследований, в т.ч. использования альтернативных методов. базирующихся на низкотемпературном воздействии на сырье, для создания экономичных технологий нефтепереработки [5-8].

Использование физических полей (электромагнитных, ультразвуковых и др.) как инструмента воздействия на жидкофазную среду является менее энергозатратным по сравнению с термокаталитическими методами активация сырья - более энергоемкими, требующими значительных капитальных затрат и дорогостоящих катализаторов.

Как известно, при волновом воздействии протекают реакции крекинга высокомолекулярных соединений нефти в более мягких условиях, чем в классических термических процессах крекинга или висбрекинга. Т.к. волновое воздействие инициирует разрыв связей в уже возбужденных относительно небольшим подогревом молекулах, его энергия расходуется только на осуществление более мягкогопроцесса термомеханического крекинга, поэтому энергетические затраты невелики, а химические реагенты и катализаторы не используются. [9-11]. 


\section{ЦЕЛЬ ИССЛЕДОВАНИЯ}

Это - изучение термомеханического - гидродинамического воздействия на тяжелую нефть и нефтяные остатки для последующей разработки технологии переработки нефтяного сырья в моторные топлива и другие продукты.

\section{СУТЬ МЕТОДА}

Применение механо-волновой активации тяжелого нефтяного сырья в гидродинамическом реакторе высокой интенсивности, с дальнейшей переработкой по существующим методам. Обработка нефтяного сырья в активаторе способствует разогреву жидкой фазы при вращении ротора, что приводит к изменению фракционного состава сырья за счет деструкции длинноцепочечных углеводородных структур [12, 13]. Гидродинамическая обработка приводит к образованию нефтяной гомогенной смеси, которая в дальнейшем подается на переработку с получением нефтепродуктов.

В работе применяли специально разработанную установку - гидродинамический роторный активатор, действие которого основано на гидродинамических эффектах при движении жидкой среды с большой скоростью с локальным изменением давления в процессе вращения, способствующем проявлению кавитационного эффекта, и с возможностью многократной повторной обработки сырья.

Алгоритм предлагаемого метода: интегрирование процесса подготовки нефтяного сырья (компаудирование, волновая обработка) с атмосферной или вакуумной перегонкой при заданной температуре разгонки. Тяжелые жидкие остаточные некондиционные продукты вновь отправляют в голову процесса. Перед механо-волновой активацией нефтяные смеси нагревали до текучего состояния при температуре $80-90^{\circ} \mathrm{C}$. После гидродинамического воздействия получаемая смесьв дальнейшем может быть также отправлена на переработку в любой подходящий для этого технологический процесс. $[14,15]$.

В лабораторных условиях была проведена атмосферная разгонка нефтяного сырья на установке согласно ГОСТ 2177-99, а также с некоторым изменением, в частности, со стабилизацией значения температур $\left(\tau^{0} \mathrm{C}\right): 190,200,220,250,260$. Регулирование стабильных температур осуществлялось с помощью термостата (SSR 40 DA, работающего в диапазоне $0-380^{\circ} \mathrm{C}$ ), термопары и ртутного термометра.

В качестве объектов исследования использовали тяжелую нефть месторождения Каражанбас, мазут, битум и смесь указанной нефти с битумом.

В таблище 1 приведены сравнительные данные показателей разгонки исходной нефти месторождения Каражанбас на образцах, отобранных в разное время.

Отгонку жидких фракций при заданной температуре проводили в течение часа, или со скоростью истечения капель до 1/30 сек. с целью наиболее полного извлечения жидкой фракции при заданной температуре скорость стекания капель составляла 1/50 сек. После отгона фракции измеряли ее массу. 


\section{ОБСУЖДЕНИЕ ПОСЛАНИЯ ПРЕЗИДЕНТА КАЗАХСТАНА}

Таблица 1 - Сравнение показателей разгонки исходной нефти месторождения Каражанбас по ГОСТ (аналитическая лабораторя Oilsert) и данных хроматографического анализа (лаборатория «Метахроманалитик»)

\begin{tabular}{|c|c|c|c|}
\hline Oilsert & \multicolumn{3}{|c|}{ «Метахроманалитик» } \\
\hline $\begin{array}{c}\text { Проба } \\
\text { январь } 2020 \text { г. }\end{array}$ & $\begin{array}{c}\text { Проба } \\
\text { июнь } 2019 \text { г. }\end{array}$ & $\begin{array}{c}\text { Проба } \\
\text { август } 2019 \text { г. }\end{array}$ & $\begin{array}{l}\text { Проба } \\
2018 \text { г. }\end{array}$ \\
\hline \multicolumn{4}{|c|}{ Температура начала кипения, ${ }^{\circ} \mathrm{C}$} \\
\hline 184 & 160,82 & 160,47 & 166,48 \\
\hline \multicolumn{4}{|c|}{ Фракционный состав, выход фрракций до температуры...ㄷ, \% } \\
\hline до, ${ }^{0} \mathrm{C}: \%$ & до ${ }^{\circ} \mathrm{C}: \%$ & до ${ }^{\circ} \mathrm{C}: \%$ & до ${ }^{0} \mathrm{C}: \%$ \\
\hline $190-0$ & $\sim 188,3 \sim 2,5$ & $\sim 191,1 \sim 2,5$ & $\sim 193,0 \sim 2,5$ \\
\hline $200-0,8$ & $\sim 204,8 \sim 3,5$ & $\sim 201,1 \sim 3,5$ & $\sim 201,0 \sim 3,0$ \\
\hline $220-2,4$ & $\sim 219,1 \sim 7,0$ & $\sim 220,1 \sim 6,5$ & $\sim 219,8 \sim 5,5$ \\
\hline $240-4,2$ & $\sim 240,2 \sim 12,5$ & $\sim 239,7 \sim 11,5$ & $\sim 239,3 \sim 9,0$ \\
\hline $260-7,6$ & $\sim 259,1 \sim 18,0$ & $\sim 259,9 \sim 17,5$ & $\sim 259,8 \sim 12,0$ \\
\hline $280-12,0$ & $\sim 280,5 \sim 26,0$ & $\sim 279,9 \sim 24,5$ & $\sim 279,8 \sim 16,5$ \\
\hline $300-16,0$ & $\sim 301,0-35,0$ & $\sim 300,0-32,0$ & $\sim 299,8-25,0$ \\
\hline $320-22,0$ & $\sim 320,4 \sim 44,0$ & $\sim 320,9 \sim 41,5$ & $\sim 320,0 \sim 31,5$ \\
\hline $340-28,0$ & $\sim 340,6 \sim 52,5$ & $\sim 340,2 \sim 51,0$ & $\sim 340,5 \sim 38,5$ \\
\hline $360-36,0$ & $\sim 360,2 \sim 60,5$ & $\sim 359,4 \sim 59,5$ & $\sim 359,8 \sim 46,5$ \\
\hline \multicolumn{4}{|c|}{ Остаток после разгонки,\%: } \\
\hline 64,0 & 39,5 & 40,5 & 53,5 \\
\hline
\end{tabular}

Из данных таблицы 1видны заметные различия показателей при обычной разгонке и при хроматографировании, однако общая тенденция - возрастание выхода продуктов с повышением температуры одинакова для обоих типов обработки сырья. Выделение легких и средних фракций (до $260^{\circ} \mathrm{C}$ ) осуществляется в относительно небольших количествах (7,5-18\%), а максимальный отгон наблюдается лишь при $360^{\circ} \mathrm{C}$.

С учетом этих, а также других расчетах при анализе результатов, мы провели разгонку нефтяного сырья при стабильных значениях задаваемых температур.

В таблице 2 приведены результаты наших исследований разгонки исходной нефти и смесей ее с битумом, а также исходных битума и мазута. Во всех экспериментах при стабильной температуре основное количество извлекаемых жидких фракций происходило, в основном, до или при достижении $260^{\circ} \mathrm{C}$, что соответствует керосиновой фракции, и значительно ниже температур при отгонке по ГОСТ (таблицьл 1 u 2).

Сравнительный анализ разгонки смесей тяжелой нефти с битумом при следующих соотношениях - 3:1; 3,06:1, 3,05:1 (cм. таблицьь 1, 2) с различной продолжительностью обработки в активаторе свидетельствует, что выход жидких фракций при температуре до $260^{\circ} \mathrm{C}$ включительно, - выше в случае гидродинамической активации на 9\% и 12\%, соответственно, для указанных смесей. Результаты отгона смесей тяжелой нефти с битумом близки к исходной тяжелой нефти (при соотношении 2:1), некоторые различия значений в области более низких температур можно отнести к погрешности эксперимента.

В процессе отгонки при атмосферном давлении улетучивались наиболее легкие составляющих жидких фракций, поэтому потери были относительно высокими с учетом продолжительности отгонки. Однако в данной серии экспериментов достигалась высокая степень извлечения жидкой фракции из нефтяного сырья. 


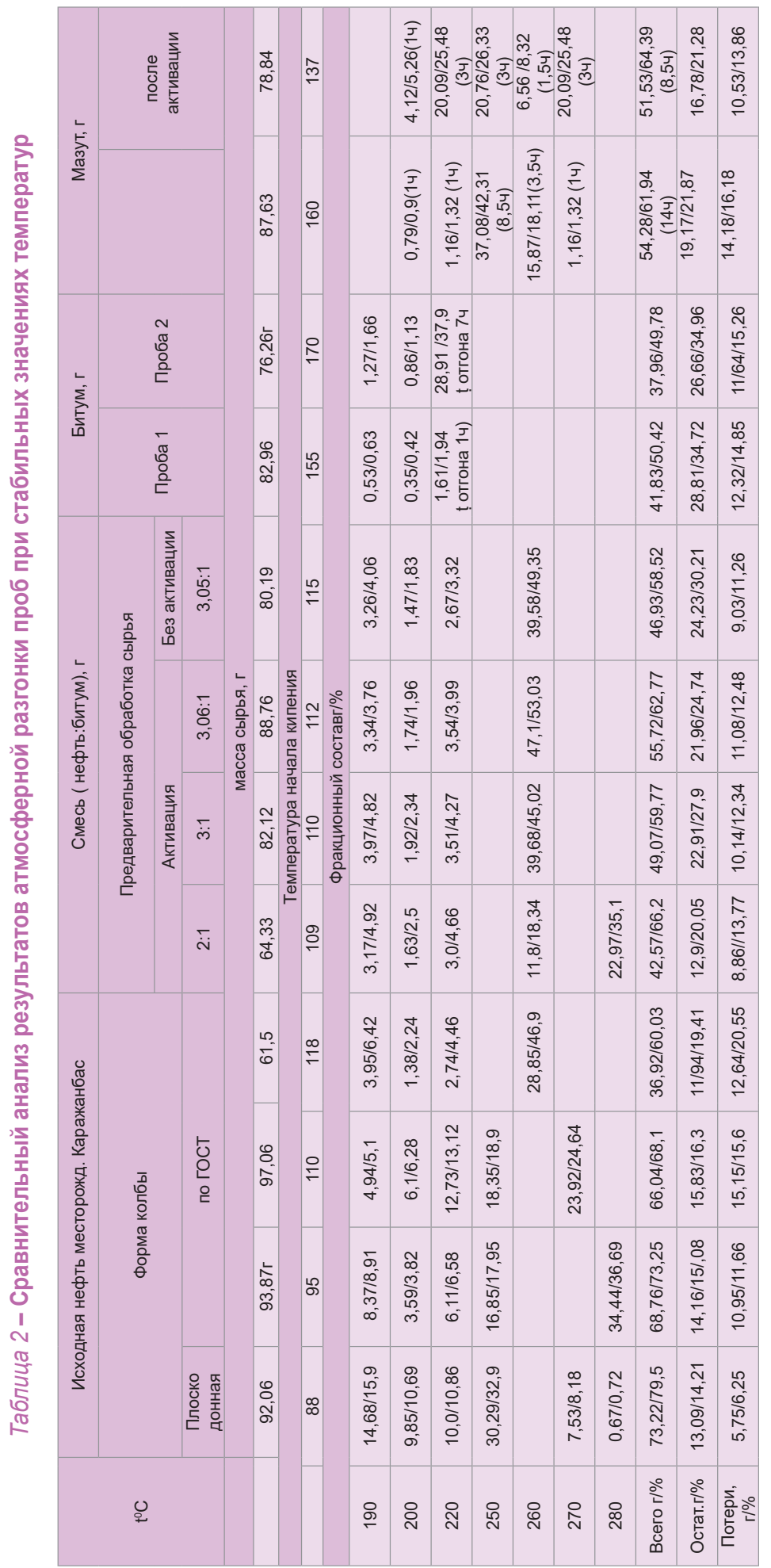




\section{ОБСУЖДЕНИЕ ПОСЛАНИЯ ПРЕЗИДЕНТА КАЗАХСТАНА}

Особый интерес представляют результаты разгонки мазута (таблища 3), осуществленной до и после гидродинамической его обработки (в интервале $94-116^{\circ} \mathrm{C}$ в течение 15 мин.). Полученные данные свидетельствуют, что наряду со снижением температуры начала кипения имеет место значительное (в разы) увеличение жидких фракций в интервале задаваемых температур $190-200^{\circ} \mathrm{C}$, и сокращение продолжительности практически полного отгона летучих фракций при почти одинаковом проценте твердого остатка $(\sim 21 \%)$.

Таблица 3 - Анализ хроматограмм мазута и его срракций, отогнанных при стабильных температурах

\begin{tabular}{|c|c|c|c|c|}
\hline \multicolumn{2}{|c|}{ Образец } & $\begin{array}{c}\text { Компонентный } \\
\text { состав } \\
\text { фракций }\end{array}$ & $\begin{array}{l}\text { Интервал температур } \\
\text { при хроматогра- } \\
\text { фрировании, }{ }^{\circ} \mathrm{C}\end{array}$ & $\begin{array}{c}\text { Доля } \\
\text { фракций }\end{array}$ \\
\hline \multicolumn{2}{|c|}{$\begin{array}{l}\text { Мазут, остаток после разгонки нефтти } \\
\text { Каражанбас до } 360^{\circ} \mathrm{C} \text { по ГОСТ }\end{array}$} & $\begin{array}{l}C_{10}-C_{16} \\
C_{17}-C_{36} \\
C_{37}-C_{44}\end{array}$ & $\begin{array}{c}212,0-325,88 \\
335,48-396,1 \\
398,12-409,34\end{array}$ & $\begin{array}{c}2,13 \\
87,54 \\
10,34\end{array}$ \\
\hline \multicolumn{2}{|c|}{ Мазут исходный } & $\begin{array}{l}C_{12}-C_{16} \\
C_{17}-C_{36} \\
C_{37}-C_{44}\end{array}$ & $\begin{array}{l}233,91-285,68 \\
297,73-393,33 \\
395,80-416,24\end{array}$ & $\begin{array}{c}3,16 \\
72,85 \\
23,99\end{array}$ \\
\hline \multicolumn{5}{|c|}{ Фракция мазута, $\mathrm{t}^{0}$ const } \\
\hline №№ & $\begin{array}{c}\text { Время разгона / } \\
\text { \% выхода }\end{array}$ & & & \\
\hline № $1-190^{\circ} \mathrm{C}$ & $14 / 0,9$ & $\begin{array}{l}\mathrm{C}_{7}-\mathrm{C}_{9} \\
\mathrm{C}_{10}^{-}-\mathrm{C}_{\mathrm{C}^{6}} \\
\mathrm{C}_{17}^{-1} \mathrm{C}^{6}\end{array}$ & $\begin{array}{c}127,72-154,58 \\
160,53-186,7 \\
207,6-235,16\end{array}$ & $\begin{array}{l}2,77 \\
66,92 \\
30,50\end{array}$ \\
\hline № $2-200^{\circ} \mathrm{C}$ & $14 / 1,32$ & $\begin{array}{l}\mathrm{C}_{7}-\mathrm{C}_{9} \\
\mathrm{C}_{10}-\mathrm{C}_{16}^{9} \\
\mathrm{C}_{17}-\mathrm{C}_{29}^{16}\end{array}$ & $\begin{array}{c}122,52-145,26 \\
154,03-179,12 \\
184,1-234,56\end{array}$ & $\begin{array}{c}4,29 \\
61,3 \\
34,41\end{array}$ \\
\hline № $3-220^{\circ} \mathrm{C}$ & $\begin{array}{l}8,5 / 42,31 \\
(3 \text { ч/14,93) }\end{array}$ & $\begin{array}{l}\mathrm{C}_{6}-\mathrm{C}_{9} \\
\mathrm{C}_{10}-\mathrm{C}_{15} \\
\mathrm{C}_{17}^{10} \mathrm{C}_{29}^{15}\end{array}$ & $\begin{array}{l}100,32-127,41 \\
133,84-158,75 \\
162,86-206,24\end{array}$ & $\begin{array}{c}9,4 \\
57,75 \\
26,04\end{array}$ \\
\hline № $4-250^{\circ} \mathrm{C}$ & $3,54 / 18,11$ & $\begin{array}{l}\mathrm{C}_{6}-\mathrm{C}_{9} \\
\mathrm{C}_{10}-\mathrm{C}^{16} \\
\mathrm{C}_{17}^{0}-\mathrm{C}_{32}^{16}\end{array}$ & $\begin{array}{c}103,41-156,09 \\
170,73-217,4 \\
220,87-287,01\end{array}$ & $\begin{array}{r}3,34 \\
4,55 \\
92,11\end{array}$ \\
\hline Всего & 14 ч/62,64 & & & \\
\hline \multicolumn{5}{|c|}{ Фракции активированного мазута , $\mathrm{t}^{0}$ const } \\
\hline №№ & $\begin{array}{c}\text { Время разгона/ } \\
\text { \% выхода }\end{array}$ & & & \\
\hline № $1-190^{\circ} \mathrm{C}$ & $14 / 5,26$ & $\begin{array}{l}\mathrm{C}_{6}-\mathrm{C}_{9} \\
\mathrm{C}_{10}-\mathrm{C}_{16} \\
\mathrm{C}_{17}-\mathrm{C}_{29}\end{array}$ & $\begin{array}{c}73,07-127,18 \\
131,63-182,61 \\
187,09-208,03\end{array}$ & $\begin{array}{c}9,09 \\
59,31 \\
31,6\end{array}$ \\
\hline № $2-200^{\circ} \mathrm{C}$ & $34 / 25,48$ & $\begin{array}{l}\mathrm{C}_{6}-\mathrm{C}_{9} \\
\mathrm{C}_{10}^{6}-\mathrm{C}^{9} \\
\mathrm{C}_{17} \mathrm{C}^{16}\end{array}$ & $\begin{array}{c}73,48-132,7 \\
135,43-167,33 \\
171,91-213,8\end{array}$ & $\begin{array}{c}9,94 \\
50,43 \\
39,63\end{array}$ \\
\hline № $3-220^{\circ} \mathrm{C}$ & $34 / 26,33$ & $\begin{array}{l}\mathrm{C}_{5}-\mathrm{C}_{9} \\
\mathrm{C}_{10}-\mathrm{C}^{9} \\
\mathrm{C}_{17}-\mathrm{C}_{31}^{16}\end{array}$ & $\begin{array}{c}70,92-129,11 \\
143,58-179,56 \\
189,03-250,34\end{array}$ & $\begin{array}{c}7,31 \\
34,68 \\
58,01\end{array}$ \\
\hline № $4-250^{\circ} \mathrm{C}$ & $1,54 / 8,32$ & $\begin{array}{l}\mathrm{C}_{5}-\mathrm{C}_{9} \\
\mathrm{C}^{10}-\mathrm{C}^{9} \\
\mathrm{C}_{17}-\mathrm{C}_{33}^{16}\end{array}$ & $\begin{array}{c}77,57-142,84 \\
152,99-191,42 \\
197,83-268,27 \\
\end{array}$ & $\begin{array}{c}6,37 \\
27,31 \\
66,32 \\
\end{array}$ \\
\hline Всего & $8,54 / 65,39$ & & & \\
\hline
\end{tabular}


Полученные результаты свидетельствуют: после гидродинамической активации выход фракций $\mathrm{C}_{9}-\mathrm{C}_{16}$ выше, чем до активации при существенном понижении температуры в случае гидрообработки образца. Исключение составляет фракция, отогнанная при $220^{\circ} \mathrm{C}$, - температурные значения для неактивированного образца мазута ниже, чем после активации. Это несоответствие объясняется тем обстоятельством, что отгонка активированного мазута проходила с большей скоростью в начальный период (190 и $\left.200^{\circ} \mathrm{C}\right)$, - было отогнано $30,75 \%(5,26 \%+25,48 \%)$ жидкой фракции, в то время как у не активированного образца при указанных значениях температур отогнано всего 2,22\% $(0,9 \%+1,32 \%)$. Т. е. отгон фракций при температуре $220^{\circ} \mathrm{C}$ проходил в условиях, когда содержание жидкой фазы в активированном образце было значительно ниже. Это и обусловило более высокие значения температур на хроматограмме для неактивированного образца, т. е. по консистенции он был более густой.

Наблюдаемое при отгонке исходного мазута высокое значение фракции $\mathrm{C}_{17}-\mathrm{C}_{36}$ (72,85\%) можно объяснить значительным превышением температурного режима разгонки - более чем на $100^{\circ} \mathrm{C}$ по сравнению с разгонкой непосредственно индивидуальных жидких фракций.

Атмосферная разгонка тяжелого нефтяного сырья со стабильным значением температур $\left({ }^{\circ} \mathrm{C}\right): 190,200,220,250$ и 260 может быть осуществлена при более низкой температуре (в интервале $90-250^{\circ} \mathrm{C}$ ) до практически сухого остатка с получением жидких фракций, кипящих при заданных значениях температур; при этом продолжительность отгонки каждой фракции зависит от толщины нагреваемого слоя жидкости, естественно, чем меньше этот показатель, тем выше скорость отгона.

Дистилляты атмосферной разгонки необработанной нефти при обычном режиме выходят светлыми; продукты обработанной нефти и разгонки при стабилизации значений температур имеют цвет отгоняемых фракций от желтоватого, рубинового до темно-коричневого, причем цветность фракций изменяется во времени: светлые постепенно темнеют. Остающийся после отгонки нефтяного сырья твердый остаток черного цвета представляет собой коксоподобный продукт, содержащий примеси, которые были в исходном сырье, в основном, это металлы; его можно подвергнуть обработке с целью извлечения ценных компонентов.

В промышленном производстве в случае неполной отгонки жидких фракций из обрабатываемого сырья (например, 45-50\%), остающуюся текучую массу можно смешивать с исходным сырьем, обрабатывать в гидродинамическом активаторе и вновь отправлять на разгонку.

Таким образом, исследования показали, что фракционный состав нефтяного сырья существенно изменяется в процессе его гидродинамической активации по сравнению с исходным не активированным сырьем. Разгонка тяжелого нефтяного сырья в интервале заданных стабилизированных значениях температур происходит с увеличением выхода легких и средних фракций и, особенно, после предварительной гидродинамической активации обрабатываемой жидкой фазы. Кроме того, процесс осуществляется при более низких значениях температур в сравнении с существующим методом разгонки.

Перечисленные факторы свидетельствуют о возможностях примененных нами методах для разработки технологий переработки тяжелого нефтяного сырья. 
Полученные результаты в определенной степени являются предварительными, поскольку при проведении экспериментов возникали вопросы, ответить на которые можно только после дополнительных исследований.

Исследования проводились в рамках научно-технической программы: BR05236739 «Создание основ производства продуктов нефте- и газопереработки на базе отечественных каталитических технологий».

\section{ЛИТЕРАТУРА}

1. Капустин В.М., Чернышева Е.А. Современное состояние и перспективы развития процессов переработки тяжелых нефтяных фрракций и остатков // Мир нефтепродуктов. - 2009. - № 9-10. - С. 20-24.

2. Banerjee D.K., Oil Sands. Heavy Oil \& Bitumen - From Recovery to Refiner // Penn Well. XVII. - 2012. - 185 p.

3. Муслимов Р.Х., Романов Г.В., Каюкова Г.П., Юсупова Т.Н., Петров С.М. Перспективы тяжелых нефтей // ЭКО. - 2012. - № 1. С. 35-40.

4. Калыбай А.А., Надиров Н.К., Бодыков Д.Т., Абжали А.К. Высоковязкие нефти, природные битумы, нефтяные остатки и переработка их вакуумно-волновой гидроконверсией // Несть и газ. - 2019. - № 2. - С. 100-119.

5. Кондрашева Н.К.,БойцоваА.А. Переработка тяжелой нефти месторождения Ярегского с использованием внешних полей // Нефтегаз.ру. - 2016. - № 4. - С. 62-66

6. Ali, M. F., and S. Abbas. 2006. A review of methods for the demetallization of residual fuel oils. Fuel ProcessingTechnology 87 (7):573-84. doi:10.1016/j.fuproc.2006.03.001.

7. Ancheyta, J. Modeling of processes and reactors for upgrading of heavy petroleum. FuelProcessingTechnology 167:99-116. doi:10.1016/j.fuproc.2017.06.015.

8. Luis C. Castaneda, Jose A.D. Munoz, Jorge Ancheyta. Current situation of emerging technologies for upgrading of heavy oils // Catalysis Today 220- 222 (2014) p.248- 256

9. Корнеев Д.С., Певнева Г.С., Головко А.К. Изменение структурных характеристик смол и асфальтенов тяжелого углеводородного сырья в термических процессах // Технологии нефти и газа. - 2016. - № 4. - С. 24-32.

10. Калыбай А.А. Энергоэффективная сверхглубокая гидроконверсия высоковязких углеводородов в моторные топлива // Нефть и газ. - 2014. - № 1. - С. 45-59.

11. D.U. Bodykov, M.S. Abdikarimov, M.A. Seitzhanova, M. Nazhipkyzy, Z.A. Mansurov, Kabdoldina A.O., UaliyevZh.R. Processing of oil sludge with the use of the electrohydraulic effect // Journal of Engineering Physics and Thermophysics. - 2017. - № 5. - V. 90.

12. Y.Ongarbayev, Sh. Oteuli, Y. Tileuberdi,G.Maldybaev\&S.NurzhanovaDemetallization and desulfurization of heavy oil residues by adsorbents.// Petroleum Science and Technology, - 2019. - Vol. 37. - P. 1045-1052. (DOI: 10.1080/10916466. 2019.1570257)

13. Nadirov N.K., Shirinskih A.V., Nurzhanova S.B., Solodova E.V., Tanybaeva A.K., Zaitova S.T. Processing technology of heavy hydrocarbons raw by mechano-wave method. The Eurasian Scientific Journal, [online] 6(11). Available at: https://esj.today/PDF/51NZVN619. pdf (in Russian) (2019).

14. Калыбай А.А., Надиров Н.К., Ширинских А.В., Нуржанова С.Б., Солодова Е.В., Заитова С.Т. Модернизация процессов переработки тяжелого нефтяного сырья // Вестник Евразийской науки. - 2019. - № 2. - С.6-11.

15. Надиров Н.К., Ширинских А.В., Нуржанова С.Б., Солодова Е.В., Абильмагжанов А.З. Новое в подготовке тяжелой нефти к переработке // Вестник Евразийской науки, 2019 №3, https://esj.today/PDF/63NZVN319.pdf (доступ свободный). 